\title{
A Comprehensive Study on the Efficacy of Copper Antifouling Coat on Biofilm-Formingorganisms in Industrial Cooling Towers
}

\author{
Nandhini S. ${ }^{1}$, Revathi K. ${ }^{2}$, Kiran Srinivasan ${ }^{3}$ \\ ${ }^{1}$ Associate Professor, Department of Microbiology, Ethiraj College for Women, Chennai-600008, Tamil Nadu, \\ India, ${ }^{2}$ Director of Research, Meenakshi Academy of Higher Education and Research, Chennai-600078, Tamil \\ Nadu, India, ${ }^{3}$ Research Scholar, Department of Microbiology, Ethiraj College for Women, Chennai-600008, Tamil \\ Nadu, India
}

\begin{abstract}
Cooling water systems serve as an ideal aquatic environment for microorganisms to proliferate and colonize. Biofouling and scaling are two major factors that adversely influence the water-cooling efficacy of industrial cooling towers, as they not only reduce the heat transfer capacity but also enhance corrosion. The present study focuses on the efficacy of copper antifouling coat applied over biofilm-forming organisms in industrial cooling towers, with a special emphasis on the quorum-sensing auto inducers and the EPS structure of organisms capable of forming the biofilm. Study results demonstrated sufficiently that copper coating has strong antifouling properties and the potential to prevent the growth of biofilm-forming organisms in industrial cooling tower systems. N-Acyl Homoserine Lactones is a major component produced bygramnegative biofilm-forming organisms, and the EPS is an important componentof all the organisms that form biofilm. The study findings led to the conclusion that use of copper antifouling paint can reduce biofilm formation and its signaling molecules in industrial cooling towers.
\end{abstract}

Keywords: Copper, Biofilm, Biofouling, Extra Polymeric Substance and N-acyl L-homoserine lactones.

\section{Introduction}

Cooling towers find an extensive application inmany large commercial buildings and residential units, such as apartment clusters. Especially industrialpower generation units andpetrochemicalindustries need a proper cooling system to removethe excess heattypically produced during many operations. In industrial operations or in residential units, coolingtower systems is an area most vulnerable to the growth and colonization of microorganisms ${ }^{[12]}$. The cooling towers

\section{Corresponding Author:}

\section{Nandhini S.}

Associate Professor, Department of Microbiology, Ethiraj College for Women, Chennai - 600008, Tamil Nadu, India

e-mail: nandhinisethurajan@gmail.com functionby the principle of removing heat from the water by the evaporationof a small portion of the water that is recirculated through the cooling unit ${ }^{[4]}$. Water released from cooling systems can harbor a variety of microorganisms, organicmatter, and minerals. The organic matter and mineral composites present in the waterprovide nutrients for the growth and colonization of microorganismsthat later form biofilms that hamper the efficacy of cooling process ${ }^{[9]}$.

Biofilm constitutes a consortium of cells that grow on a surface and are embedded within a thick mucilaginous matrix composed of extracellular polymeric substance [EPS]. Biofouling is considered to pose a detrimental effect in thewater recirculationprocess of coolingtower systems which are constantly exposed to water harboring bacteria as well as nutrients in most of the industrial settings. The formation of biofilms by microorganisms has been reported frequently in industrial cooling towers, and its resistance to disinfectants is another 
complication. The signaling molecules N-Acyl HomoSerine Lactone play avital role in biofilm formation and in the development of resistance to available disinfectants [3]. Quorum sensing has emerged as a hot topic in recent times, and it is defined as the mechanism by which different species of bacteria communicate with one another. The acyl homoserine lactone [AHL] molecules are the best-studied autoinducers that serve the purpose of primary quorum-sensing signals used bygram-negative bacteria and in the case of gram-positive bacteria, they rely on peptide-based autoinducers and structural EPS ${ }^{[8]}$.

Numerous studies have reported on the efficacy of the application of copper antifouling on the superstructures or surface areas of marine transport systems, including submarines and ships, and have shown enough evidence that the application of paint mixed with copper-based antifoulants can help prevent biofouling and corrosion to a large extent.In this study, the efficacy of antifouling copper coat on biofilm forming organisms in industrial cooling towers was studied with a special emphasis on quorum-sensing molecules and the EPS.

\section{Materials and Method}

Specimen Collection: Biofilm samples were collected from Thirumalai Chemicals Limited, Vellore, Chennai and also from Ultra Marine and Pigments Ltd, Vellore, Tamil Nadu. Using sterile scalpels, the surface biofilms found in the cooling tower panel werescrapped at four different points of each of these cooling towers and later collected in two sterile containers. The circulating water from thecooling tower was used as a transport medium for samplepreservation. Next, samples were stored in thermocol ice packs for maintaining the environmental viability of microorganisms that survived in the conditions of cooling tower and were transported to the lab. Water samples from the cooling towerswere also collected in sterile cans for further use in order to study the propagation of microorganisms.

Test materials: Galvanized stainless steel coupon and copper-coated stainless steel coupons were used as test and control samples after welding to obtain a dimension of $20 \times 20 \times 0.5 \mathrm{~mm}$.

Experimental Setup: Copper and stainless steel [SS] coupons were subjected to surface sterilizationusing $70 \%$ ethanol and were incubated as test and control systems, respectively, in both industries for aperiod of 45 days ${ }^{[6]}$.

Sample processing and isolation of organism: A presumptive wet mount for the purpose of microscopic observationwas performed to identifyalgal colonies. Heterotrophic plate count was then performed to qualitatively analyzethe bacterial colonies present in the biofilm and in the water samples.

\begin{tabular}{|c|c|}
\hline Figure 1: Biofilm sample from Ultra Marine & Figure 2: Cooling tower water sample from Ultra \\
\hline Pigments Ltd. & Marine Pigments Ltd. \\
\hline Figure 3 Biofilm sample from Thirumalai Chemicals & Figure 4 Cooling Tower water sample Thirumalai \\
\hline Ltd. & Chemicals Ltd. \\
\hline
\end{tabular}


Identification of bacteria: Significant bacterial isolates were identified in accordance with Bergey's manual that provides data such as colony characteristics, staining reaction, and biochemical properties. For further confirmation, isolates weresent to the lab at NCIM, Pune, to subject them to $16 \mathrm{~S}$ rRNA sequencing and use the results for further analysis.

Collection of incubated coupons: Copper and SS coupons were collected using sterile ziplock bags filled with cooling tower water after an incubation period of 45 days. Macroscopic observation of patterns of biofilm formationwascarried out for all the coupons.

Isolation of biofilm: Mucilaginous biofilms were collected in sterile containers by scraping the respective coupons under sterile conditions.

\section{Extraction of $\mathbf{N}$-acyl homoserine lactone, purification, and quantification: Modified} physiochemical extraction and purification was carried out to analyze the samples through FTIR ${ }^{[5]}$. As much as $200 \mathrm{ml}$ of LB Broth was inoculated with $1 \mathrm{ml}$ biofilm suspension for each experimental setup (Sample1-TCL SS, Sample 2-TCL Cu, Sample 3-UMP SS, Sample 4-UMP $\mathrm{Cu})$ and incubated overnight at $35^{\circ} \mathrm{C}(100 \mathrm{rpm})$. After incubation, culture suspensions were transferred to sterile centrifuge tubes that were labeled as Sample 1-TCL SS, Sample2-TCL Cu, Sample3-UMP SS, Sample4-UMP $\mathrm{Cu}$, respectively. These suspensions were subjected to centrifugation at $15,000 \mathrm{rpm}, 4^{\circ} \mathrm{C}$ for 20 minutes. The supernatant was then filtered using a membrane filtration apparatus with membrane of 0.22 $\mu \mathrm{m}$ pore size. For purification, $200 \mathrm{ml}$ of the filtrate obtained was mixed with $100 \mathrm{ml}$ ethyl acetate in $2: 1$ ratio and was incubated in a shaker for 10 minutes at $100 \mathrm{rpm}{ }^{[16]}$. Then the mixture was subjected to liquidliquid extraction using a separating funnel for obtaining twoimmiscible layers using the FTIR-grade DMSO as solvent. Subsequently, the upper organic layer was collected in sterile containers. The extract was used as AHL sample andwas further analyzed through FTIR.

Extraction and Quantification of EPS: Physical method was used for extracting extracellular polymeric substances ${ }^{[2]}$. Biofilm samples were transferred to sterile centrifuge tubes labeled differently (Sample 1-TCL SS, Sample2-TCL Cu, Sample3-UMP SS, Sample4-UMP $\mathrm{Cu})$ and subjected to centrifugation at $20,000 \mathrm{rpm}, 4^{\circ} \mathrm{C}$ for 20 minutes. The supernatant was then filtered using a membrane filtration apparatus with membrane of 0.22 - $\mu \mathrm{m}$ pore size. The filtrate was used as the EPS sample, and quantification was carried out by performing protein and sugar estimation following the Phenol- Sulfuric method and Bradford method, respectively.

Invitro biofilm propagation: Microtitre Plate method was performed for studying the properties ofbiofilm formation from the obtained samples ${ }^{[11]}$.

Test 1-A mixture of bacterial isolates from the Nutrient Agar plates (TCL-SS and $\mathrm{Cu}$; UMP-SS and $\mathrm{Cu}$ ) were transferred to sterile LB broth for all the samples.

Test 2-About $2 \mathrm{ml}$ of the preserved biofilm sample was transferred to a sterile test tube and further processed.

Propagation of Biofilms: The samples from Test 1 and Test 2 wereculturedin an LB medium withovernight incubation. The overnight culture was then diluted 1:100 using fresh medium for biofilm assays. A quantity of $100 \mu \mathrm{L}$ of dilution was added into each well in a 96well dish. A total of eight replicates were maintained. The microtiter plate was then subjected toincubation for up to 24 hours at $37^{\circ} \mathrm{C}$.Afterincubation, unattached cells were dumped out of the plate by turning the plate and rinsing thoroughly by gently submergingin a small tub of water. This process was repeated one more time to removeunattached cells, and media components were stained in the next step, thereby significantly lowering the background staining. About $125 \mu \mathrm{L}$ of $0.1 \%$ solution of crystal violet was added into the water of each well of the microtiter plate. The microtiter plate was subjected to incubationat room temperature for 10 to 15 minutes. Then the plate was rinsed 3 to 4 times with water and blotted onto a stack of paper towels to remove excess cells and dye. The microtiter plate was turned upside down and dried for few hours or overnight andlater photographed after drying.

Quantification of the Biofilm: A quantity of $125 \mu \mathrm{L}$ of $30 \%$ acetic acid was added to water in each well of the microtiter plate for solubilization of $\mathrm{CV}$. The microtiter plate was kept undisturbed at room temperature for 10 to 15 minutes. Next, $125 \mu \mathrm{L}$ of solubilized $\mathrm{CV}$ was added to a new flat-bottomed microtiter dish, and the absorbance was quantified in a plate reader at $550 \mathrm{~nm}$ using $30 \%$ acetic acid in water as the blank.

Statistical Analysis: The $z$ score test for the two population proportions was used for determiningthe significance of difference between the biofilm-forming potentials of Test 1 and Test 2 . The test of significance 
was set at $<.05$. Two-tailed hypothesis was selected for this study.

\section{Results}

Identification of Biofilm sample: The algal colonies obtained were identified as Nostoc spp, Chlorella spp, Lyngbya spp, and Synechococcus spp. A total of $35 \times 10^{6} \mathrm{CFU} / \mathrm{ml}$ and $40 \times 10^{6} \mathrm{CFU} / \mathrm{ml}$ was obtained from the samples collected from TCL and UMP, respectively. Three colonies each from TLC and UMP were isolated and further subjected to processing for obtaining pure cultures. Table 1 and 2 show the colony morphology oforganisms isolated from the TCL and UMP samples.Fig. 5 to 10 show the colony morphology of microorganisms from the TCL and UMP samples on a nutrient agar medium.

Table 1 Colony morphology of organisms from TCL

\begin{tabular}{|l|c|c|c|c|c|c|c|}
\hline Colony & Size & Shape & Elevation & Margin & Opacity & Surface & Chromogenesis \\
\hline Micrococcus luteus & $2-4 \mathrm{~mm}$ & Round & Raised & Entire & Opaque & Yellow & Yellow \\
\hline Burkholderia cepacia & $1-2 \mathrm{~mm}$ & Round & Convex & Entire & Opaque & $\begin{array}{c}\text { Creamy } \\
\text { white }\end{array}$ & None \\
\hline Bacillus megaterium & $1-2 \mathrm{~mm}$ & Round & Raised & Entire & Translucent & White & None \\
\hline
\end{tabular}

Table 2 Colony morphology of organisms from UMP

\begin{tabular}{|l|c|c|c|c|c|c|c|}
\hline Colony & Size & Shape & Elevation & Margin & Opacity & Color & Chromogenesis \\
\hline Bacillus subtilis & $1-2 \mathrm{~mm}$ & Round & Raised & Rough & Opaque & White & None \\
\hline Sarcina aurantiaca & $2-4 \mathrm{~mm}$ & Round & Raised & Entire & Opaque & Orange & Orange \\
\hline Pseudomonas putida & $2-4 \mathrm{~mm}$ & Round & Convex & Entire & Translucent & White & None \\
\hline
\end{tabular}

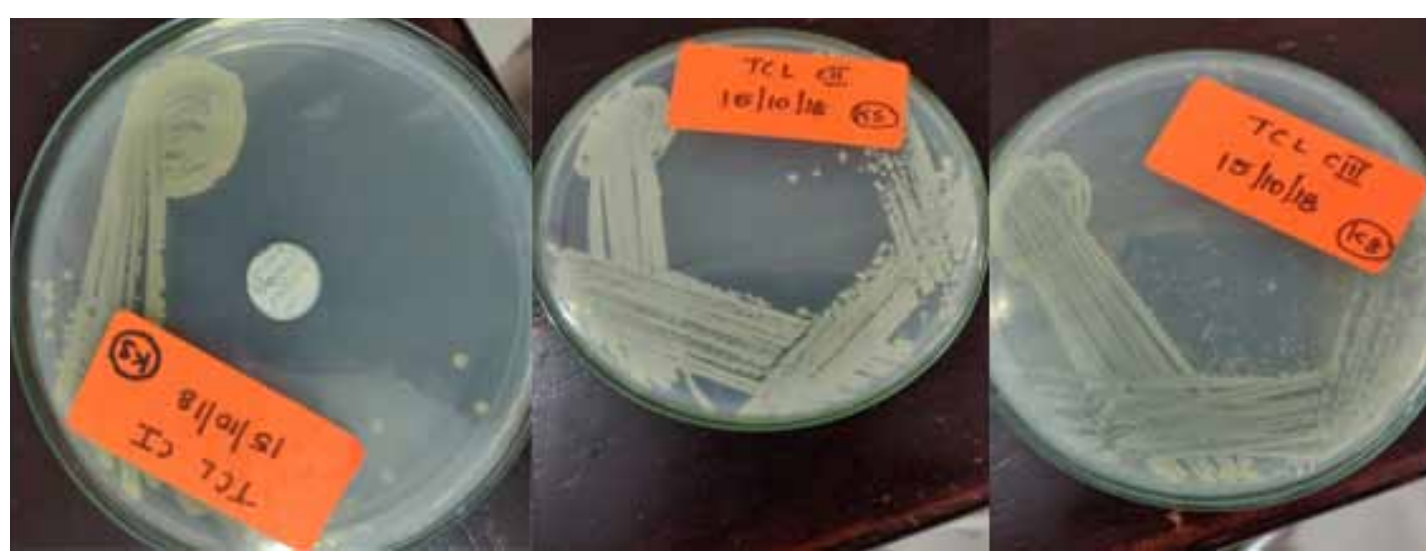

Figure 5 Colony 1

Figure 6 Colony 2

Figure 7 Colony 3

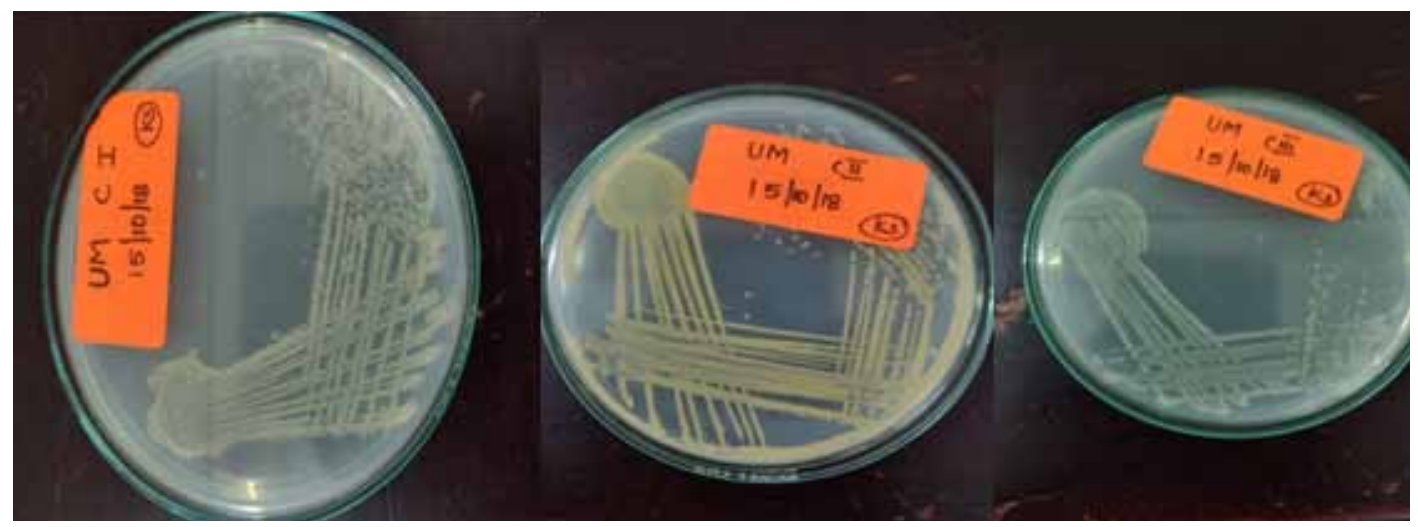

Figure 8 Colony 4

Figure 9 Colony 5

Figure 10 Colony 6 


\section{Estimation of EPS:}

Sugar Estimation by Phenol Sulfuric Method: Sugar content in coupons obtained from TCL industries was estimated to be $4.89 / 100 \mathrm{ml}$ in SS coupons and $3.14 / 100 \mathrm{ml}$ in $\mathrm{Cu}$ coupons. A significant decrease was observed in sugar concentration. Sugar content in coupons collected from UMP industries was estimated to be $1.99 / 100 \mathrm{ml}$ in $\mathrm{SS}$ coupons and $1.07 / 100 \mathrm{ml}$ in $\mathrm{Cu}$ coupons. A very minute decrease was observed in sugar concentration. Fig. 11is a graphical representation of sugar estimate of TCL (SS, Cu) and UMP (SS, Cu).

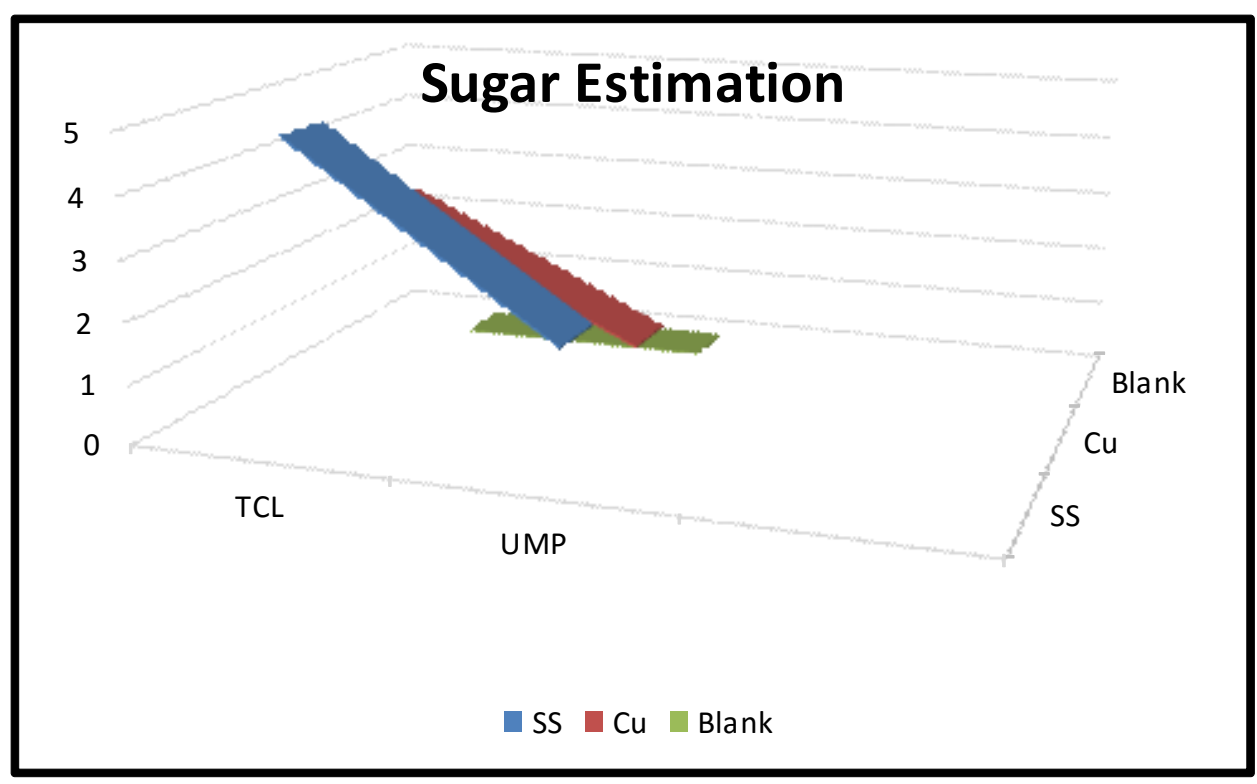

Figure 11 Graphical representation of sugar estimate of TCL (SS, Cu) and UMP (SS, Cu)

Protein Estimation by Bradford's Method: The protein content in coupons from TCL industries was estimated to be $4.3 / 100 \mathrm{ml}$ in SS coupons and 3.98/100ml in $\mathrm{Cu}$ coupons. A slight decrease in protein concentration was observed. The protein content in coupons from UMP industries was estimated to be $2.14 / 100 \mathrm{ml}$ in SS coupons and $1.22 / 100 \mathrm{ml}$ in $\mathrm{Cu}$ coupons. A significant decrease in protein concentration was observed. Figure 12 is a graphical representation of estimate protein content in TCL (SS, Cu) and UMP (SS, Cu) samples.

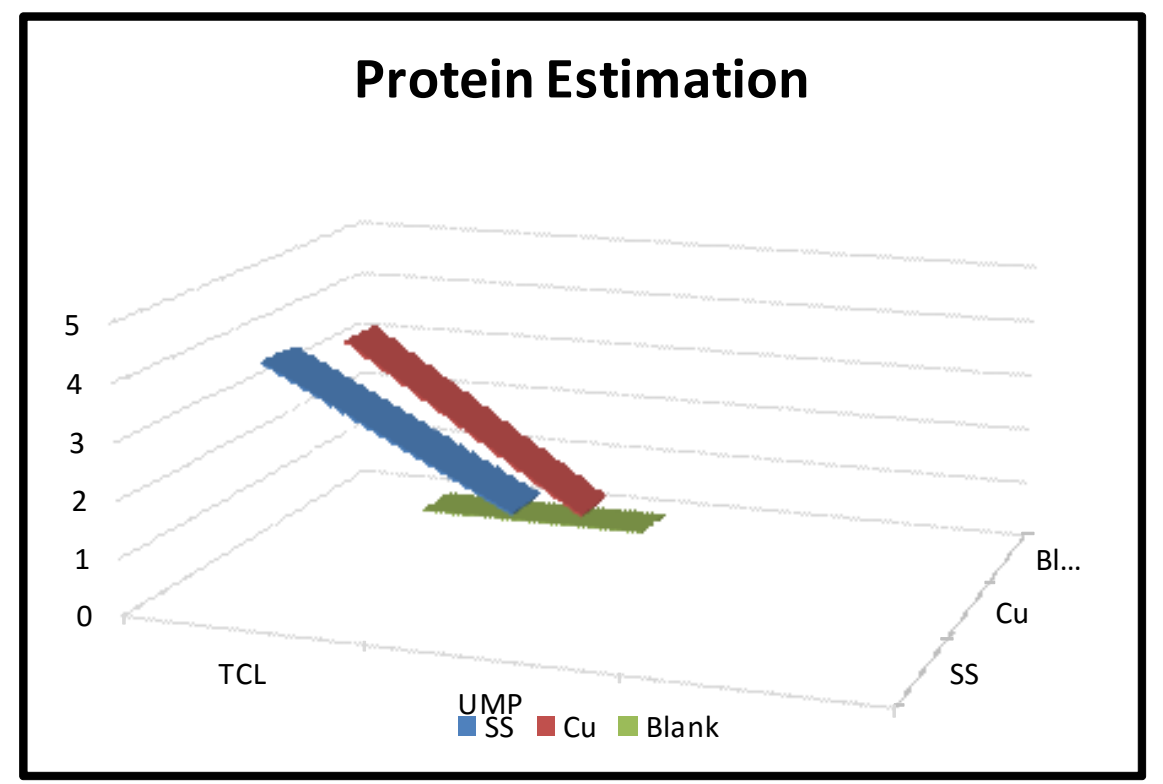

Figure 12 Graphical representation of protein estimate of TCL (SS, Cu) and UMP (SS, Cu) 
Quantification of AHL by FTIR: The AHL 3-UMP SS, Sample 4-UMP Cu) were subjected to FTIR extract of two samples of SS and CU from TCL and analysis, and the observations are presented as follows. UMP (Sample 1-TCL SS, Sample 2-TCL Cu, Sample

\section{Sample1-TCL SS}

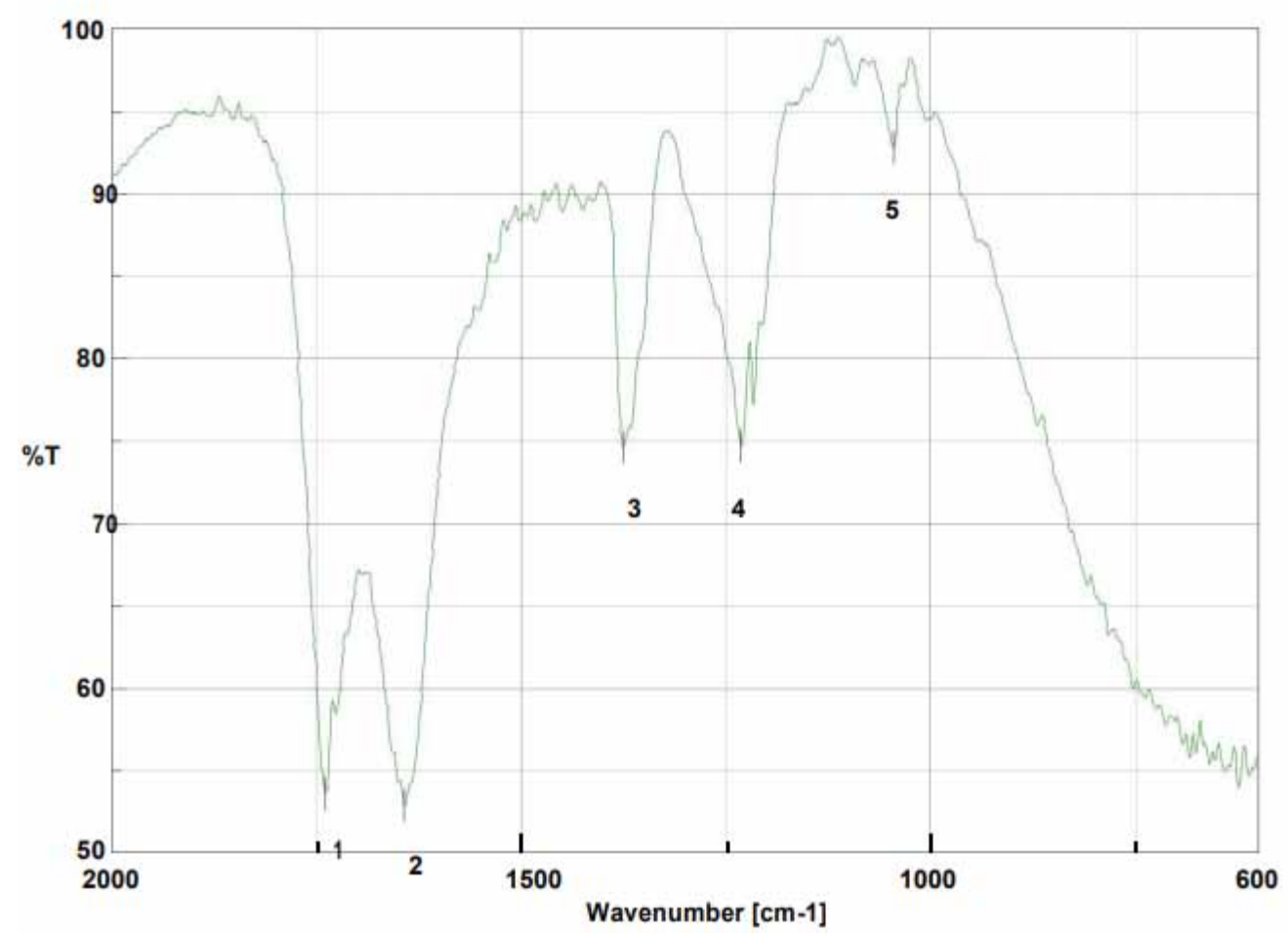

Figure 13 Graphical Representation of FTIR spectra for TCL SS

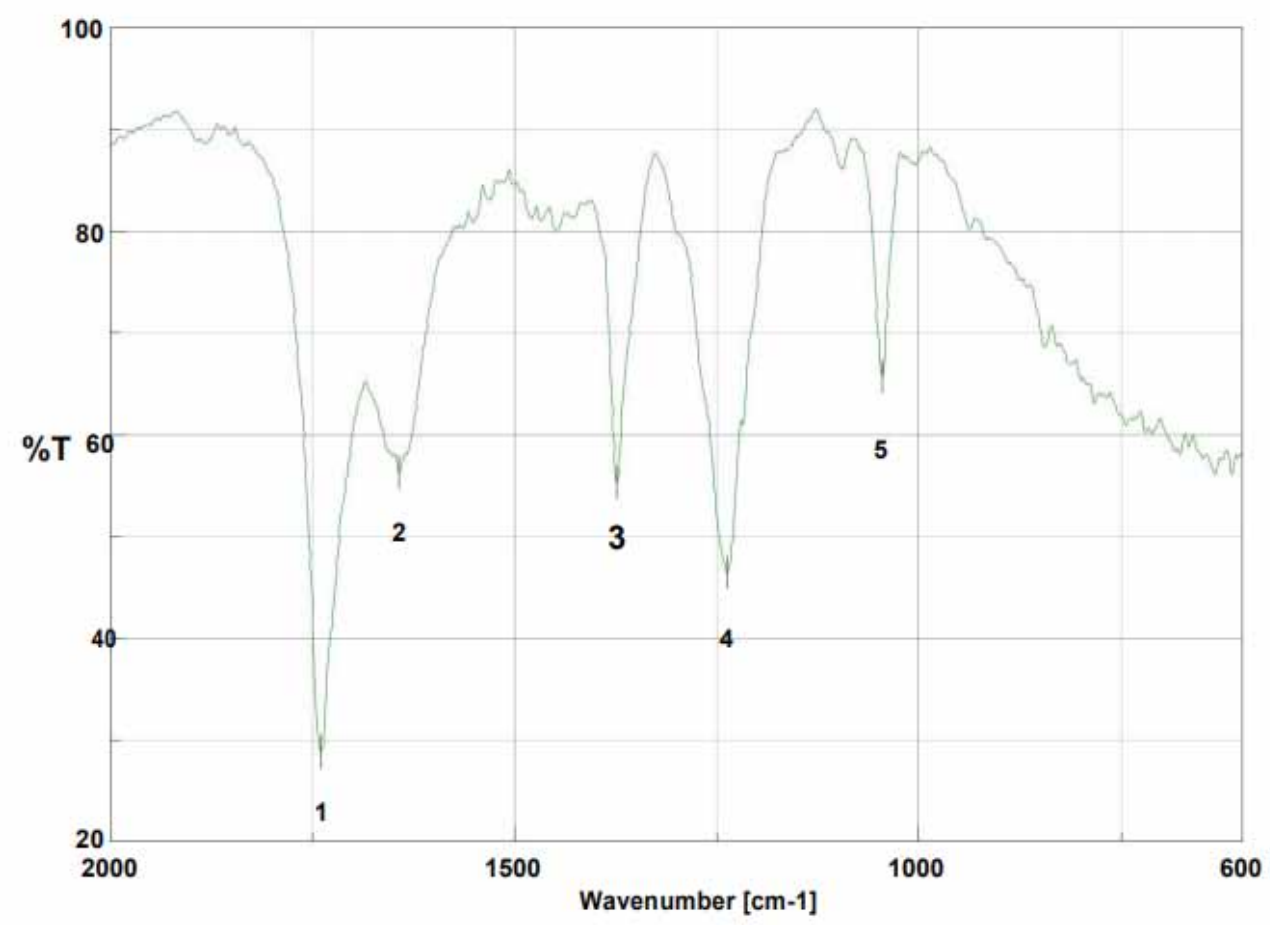

Figure 14 Graphical Representation of FTIR spectra for TCL Cu 
Sample 3-UMP SS:

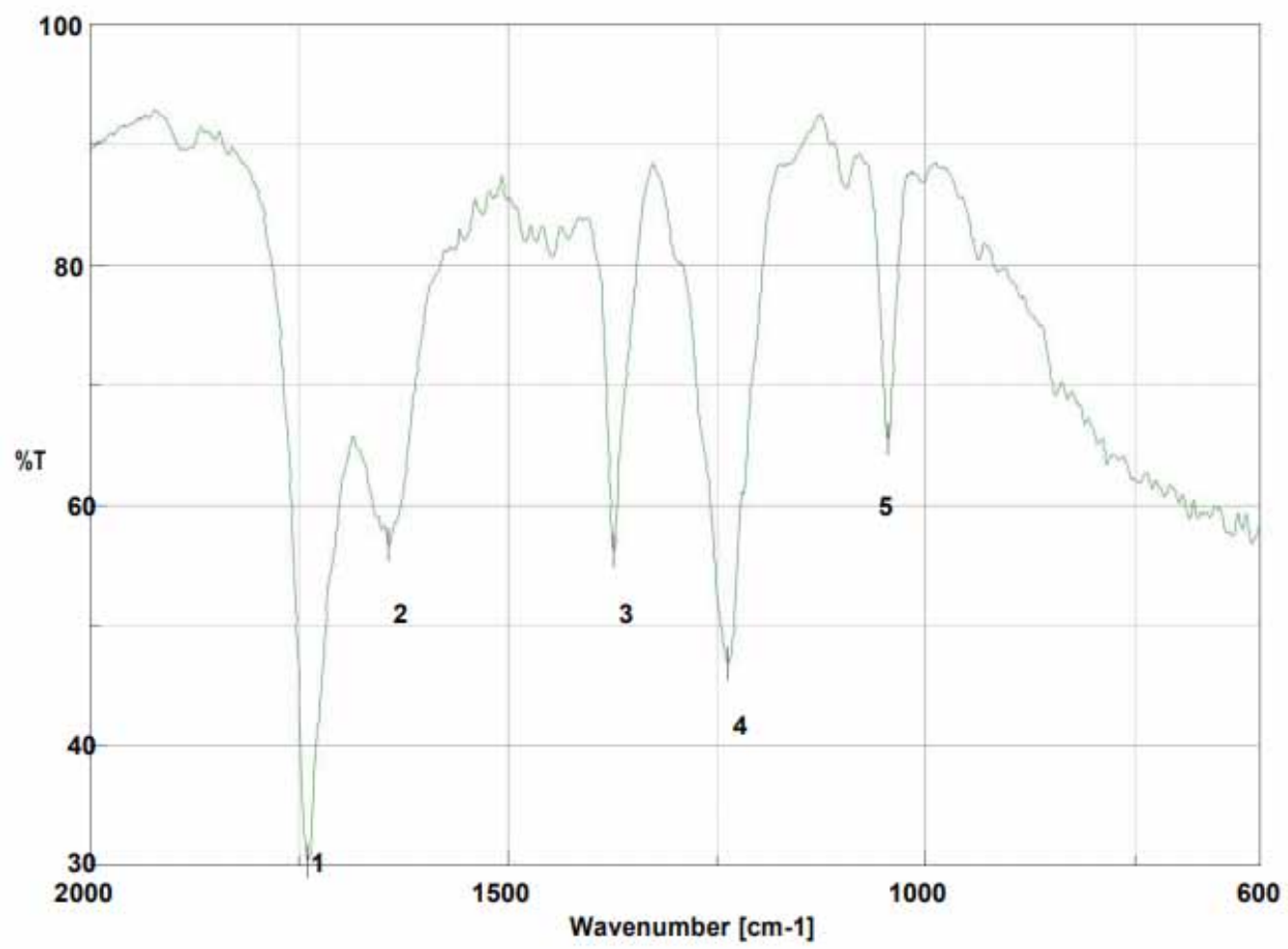

Figure 15 Graphical Representation of FTIR spectra for UMP SS

Sample 4-UMP Cu:

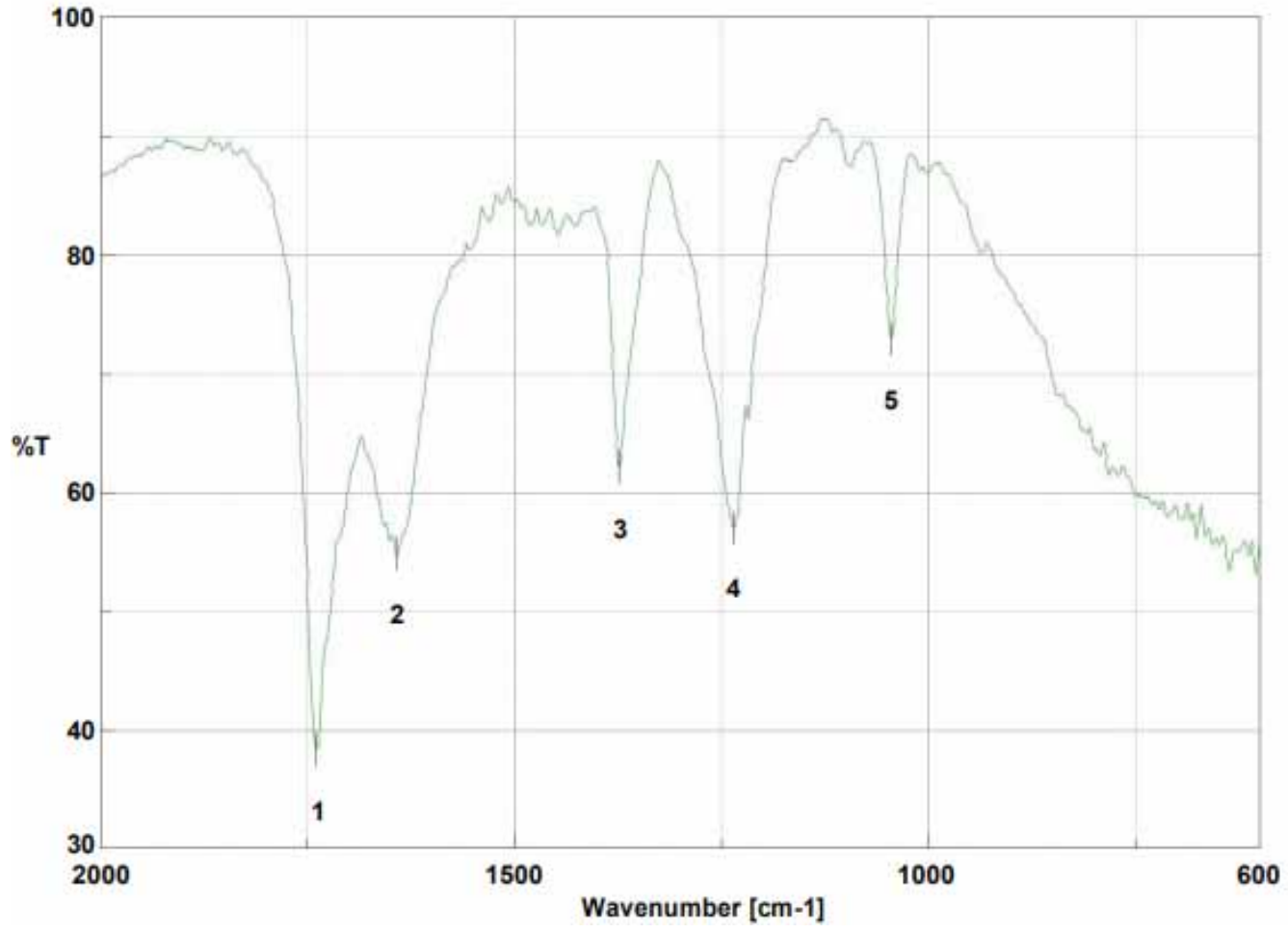

Figure 16 Graphical Representation of FTIR spectra for UMP Cu 
Table 3 FTIR analysis for TCL SS

\begin{tabular}{|c|c|c|c|c|}
\hline S. No. & Position & Intensity & Frequency Range (cm ${ }^{-1)}$ & Functional Groups \\
\hline 1 & 1739.48 & 53.6007 & $2000-1500$ & C $=\mathrm{O}$ lactone ring \\
\hline 2 & 1643.05 & 52.8837 & $2000-1500$ & $\mathrm{C}-\mathrm{H}(\mathrm{alkyl})$ \\
\hline 3 & 1375.96 & 74.5949 & $1500-1000$ & $\mathrm{C}-\mathrm{O}(\mathrm{aromatic})$ \\
\hline 4 & 1231.33 & 74.6818 & $1500-1000$ & $\mathrm{C}=\mathrm{O}$ lactone ring \\
\hline 5 & 1045.23 & 92.7753 & $1500-1000$ & $\mathrm{~N}=\mathrm{H}(\mathrm{amine})$ \\
\hline
\end{tabular}

Sample 2-TCL Cu:

Table 4 FTIR analysis for TCL Cu

\begin{tabular}{|c|c|c|c|c|}
\hline S. No. & Position & Intensity & Frequency Range $\left(\mathbf{c m}^{-\mathbf{1}}\right)$ & Functional Groups \\
\hline 1 & 1740.44 & 28.799 & $2000-1500$ & $\mathrm{C}=\mathrm{O}$ lactone ring \\
\hline 2 & 1643.05 & 56.3256 & $2000-1500$ & $\mathrm{C}-\mathrm{H}(\mathrm{alkyl})$ \\
\hline 3 & 1374.03 & 55.2883 & $1500-1000$ & $\mathrm{C}-\mathrm{O}(\mathrm{aromatic})$ \\
\hline 4 & 1237.11 & 46.5075 & $1500-1000$ & $\mathrm{C}=\mathrm{O}$ lactone ring \\
\hline 5 & 1045.23 & 65.7366 & $1500-1000$ & $\mathrm{~N}=\mathrm{H}(\mathrm{amine})$ \\
\hline
\end{tabular}

Table 5 FTIR analysis for TCL UMP SS

\begin{tabular}{|c|c|c|c|c|}
\hline S. No. & Position & Intensity & Frequency Range (cm $\left.{ }^{-1}\right)$ & Functional Groups \\
\hline 1 & 1739.48 & 38.2943 & $2000-1500$ & C=O lactone ring \\
\hline 2 & 1643.05 & 54.7616 & $2000-1500$ & C-H (alkyl) \\
\hline 3 & 1374.03 & 62.088 & $1500-1000$ & C-O (aromatic) \\
\hline 4 & 1235.18 & 56.9419 & $1500-1000$ & C=O lactone ring \\
\hline 5 & 1045.23 & 72.915 & $1500-1000$ & $\mathrm{~N}=\mathrm{H}(\mathrm{amine})$ \\
\hline
\end{tabular}

Table 6 FTIR analysis for UMP Cu

\begin{tabular}{|c|c|c|c|c|}
\hline S. No. & Position & Intensity & Frequency Range (cm $\left.\mathbf{~}^{\mathbf{1}}\right)$ & Functional Groups \\
\hline 1 & 1740.44 & 30.2544 & $2000-1500$ & C=O lactone ring \\
\hline 2 & 1643.05 & 56.6761 & $2000-1500$ & C-H (alkyl) \\
\hline 3 & 1374.03 & 56.1789 & $1500-1000$ & C-O (aromatic) \\
\hline 4 & 1237.11 & 46.7873 & $1500-1000$ & C=O lactone ring \\
\hline 5 & 1045.23 & 65.4578 & $1500-1000$ & $\mathrm{~N}=\mathrm{H}(\mathrm{amine})$ \\
\hline
\end{tabular}

Table 7 Absorbance Reading at 550nm for Test1

\begin{tabular}{|c|c|c|c|c|}
\hline Replicates & TCL SS & TCL Cu & UMP SS & UMP Cu \\
\hline 1 & 0.738 & 0.622 & 0.733 & 0.107 \\
\hline 2 & 0.991 & 0.534 & 0.688 & 0.152 \\
\hline 3 & 1.02 & 0.213 & 0.652 & 0.278 \\
\hline 4 & 0.866 & 0.610 & 0.991 & 0.497 \\
\hline 5 & 0.931 & 0.332 & 1.02 & 0.442 \\
\hline 6 & 0.986 & 0.634 & 0.866 & 0.248 \\
\hline
\end{tabular}




\begin{tabular}{|c|c|c|c|c|}
\hline Replicates & TCL SS & TCL Cu & UMP SS & UMP Cu \\
\hline 7 & 1.34 & 0.277 & 0.931 & 0.285 \\
\hline 8 & 1.61 & 0.098 & 0.986 & 0.101 \\
\hline
\end{tabular}

Table 8 Absorbance Reading at 550nm for Test2

\begin{tabular}{|c|c|c|c|c|}
\hline Replicates & TCL SS & TCL Cu & UMP SS & UMP Cu \\
\hline 1 & 1.04 & 0.345 & 0.733 & 0.213 \\
\hline 2 & 0.508 & 0.431 & 0.868 & 0.177 \\
\hline 3 & 0.997 & 0.342 & 1.098 & 0.235 \\
\hline 4 & 1.525 & 0.522 & 0.955 & 0.198 \\
\hline 5 & 0.773 & 0.123 & 1.004 & 0.236 \\
\hline 6 & 0.607 & 0.269 & 0.835 & 0.312 \\
\hline 7 & 0.677 & 0.287 & 0.829 & 0.145 \\
\hline 8 & 0.969 & 0.512 & 0.776 & 0.188 \\
\hline
\end{tabular}

Microtitre Biofilm Formation Assay: The adsorption readings at $\mathrm{OD}_{550}$ of cultures from Test 1 and Test 2 after staining the formed biofilmsamples with crystal violet helped to identify a substantial difference between the isolates of $\mathrm{SS}$ and $\mathrm{Cu}$ coupons collected from TCL and UMP.

The $Z$ score test was carried out for the two population proportions to determine the significance of difference between the biofilm-forming capabilities of Test 1 and Test 2 , and results were found to be significant at $p<.05$ for both the tests.

\section{Discussion}

Crude biofilm and water samples were collected from Thirumalai Chemicals Limited (TCL) and Ultra Marine and Pigments Ltd (UMP), Vellore. Preliminary microscopic examination revealed algal colonies such as Nostoc spp, Chlorella spp, Lyngbyaspp, and Synechococcus spp. They occur widely in aquatic habitats and form active biofilms due to production of alkaloid compounds and intense pigmentation on surfaces exposed to moisture (Sanmartín et al, 2010).

A homogenized form of biofilm and cooling-towerwater samples was subjected to heterotrophic plate count using LB mediaforenumeration of bacterial colonies. Three colonies exhibiting maximum characteristic growth from both samples were selectedand subjected to gram staining, motility, and biochemical tests (Indole, Methyl Red, Voges Proskauer, Citrate, and TSI) for identification. The process of identification revealed
Micrococcus luteus, Burkholderia cepacia, and Bacillus megaterium from TCL, and Bacillus subtilis, Sarcinaaur antiaca, and Pseudomonas putida from UMP. Further confirmation of the isolateswas done by subjecting the identified organisms to $16 \mathrm{SrRNA}$ sequencing.

Micrococcus luteus is a gram-positive as well as gram-variable coccus; it is as a protrophic and nonmotile bacteria residing in water released by industrial systems. In a study [15], the biofilm-forming abilities of the organism in a microtiter plate test was studied. Burkholderia cepacia is an aerobic gram-negative bacillus that occurs in various aquatic environments. It is of low virulence and is a frequent colonizer of fluids. In a study ${ }^{[13]}$, it was reported that even the non-mucoidal stage of the organism is capable of producing biofilms effectively. Bacillus megaterium is considered a grampositive, endospore-forming, rod-shaped, aerobic, and saprophytic bacteria that produces a variety of enzymes and proteins. Currently, active research is taking place to study this organism's capacity for biofilm formation after manipulation of its genome for bioremediation. Bacillus subtilis are a gram-positive, aerobic, rodshaped, and catalase-positive bacterium. In study [10] the extracellular matrix produced by Bacillus subtilis B-1, an environmental strain capable of forming robust floating biofilms, was studied.

Sarcina aurantiaca are gram-positive bacteria that forma characteristic packet of cells in both solid and liquid media. They produce a characteristic orange pigmentation ${ }^{[1]}$ studied the diverse genomic profiles 
and heterogeneity of the biofilm capabilities of Sarcina aurantiaca and other archaic organisms. Pseudomonas putidaare a rod-shaped, flagellated, gram-negative bacteria that occurs in most of the soil and water habitats. A study ${ }^{[7]}$ revealed the complex water-soluble EPS produced by the organismcontaining polysaccharides in a larger proportion.

For testing the efficacy ofcopper antifouling coat onbiofilm, a control (Stainless Steel-SS) and test (Copper$\mathrm{Cu}$ ) system was installed at the cooling tower panel. We ensured the SS and $\mathrm{Cu}$ coupons were subjected to the same water circulation system. This setup was followed for both the industries. Coupons were incubated for 45 days for the completion of primary attachment assay and microcolony formation. The autoinducers [N-Acyl Homoserine Lactones] and the tensile EPS structure are the two major compounds produced during these stages. After the 45-days incubation, the biofilm-laden $\mathrm{SS}$ and $\mathrm{Cu}$ coupons were subjected to the extraction of quorum-sensing molecules as well as the EPS structure for both TCL and UMP samples. AHL molecules were extractedusing the physiochemical method and were later purified by liquid-liquid extraction. The samples were further analyzed by FTIR.

The SS and $\mathrm{Cu}$ AHL extracts from TCL were analyzed for the presence of AHL functional groups, which included the $\mathrm{C}=\mathrm{O}$ lactone and a $\mathrm{N}-\mathrm{H}$ amine group. The $\mathrm{C}=\mathrm{O}$ lactone ring from $\mathrm{SS}$ exhibited peak intensity at 53.6007 and 74.6818 at two different frequency ranges. The $\mathrm{N}-\mathrm{H}$ amine group was at a peak intensity of 92.7753, and for the $\mathrm{Cu}$, it was 28.799; for the lactone rings, 46.5075; and for the N-H group, 65.7366. This occurrence of the N-H amine group was the fingerprint region and confirmed the decreasein AHL activity between the biofilm sample extracted from $\mathrm{SS}$ and $\mathrm{Cu}$ coupons. Subsequently, the SS and Cu AHL extracts from UMP were analyzed for the presence of AHL functional groups, where the $\mathrm{C}=\mathrm{O}$ lactone ring from $\mathrm{Cu}$ demonstrated peak intensity at 30.2544 and 46.7873 at two different frequency ranges. The $\mathrm{N}-\mathrm{H}$ amine group occurred at 65.4578 . For the SS, it was 38.2943, and it was 56.9419 for the lactone rings while 72.915 for the N-H group. The second peak of the lactone ring exhibited higher intensity in the $\mathrm{Cu}$ sample, but the $\mathrm{N}-\mathrm{H}$ fingerprint region exhibited a decreased peak intensity. These results confirm the decrease in AHL activity between the biofilm samplesthat were extracted from SS and $\mathrm{Cu}$ coupons.
The EPS structure is composed of only two major components-sugars and protein. Total carbohydrate concentration was estimated by the phenol-sulfuric method, and it was found to be $4.89 / 100 \mathrm{ml}$ and $3.14 / 100 \mathrm{ml}$ in $\mathrm{SS}$ and $\mathrm{Cu}$ coupons, respectively, for the TCL sample, and $1.99 / 100 \mathrm{ml}$ and $1.07 / 100 \mathrm{ml}$ in $\mathrm{SS}$ and $\mathrm{Cu}$ coupons, respectively, for the UMP sample. Total protein was estimated to be $4.3 / 100 \mathrm{ml}$ and $3.98 / 100 \mathrm{ml}$ in $\mathrm{SS}$ and $\mathrm{Cu}$ coupons, respectively, for the TCL sample and $2.14 / 100 \mathrm{ml}$ and $1.22 / 100 \mathrm{ml}$ in SS and $\mathrm{Cu}$ coupons, respectively, for the UMP sample. A considerable difference of significance was found in the total carbohydrate estimated and a slight difference in protein content as estimated. When the total estimated values of carbohydrate and total protein were added, a significant difference in the concentration of the EPS extract was observed. Microtiter biofilm formation was performed for assessing the biofilm-forming capabilities of bacterial isolates from the TCL and UMP samples, and the method allowed for an invitro propagation of the biofilm sample. The isolated bacterial isolates from SS and $\mathrm{Cu}$ coupons were taken as Test 1 . Upon propagation, staining with crystal violet, and subsequent calculation of absorbance rate in ELISA plate reader, the total absorbance of the 8 replicates was found to be 8 (SS) and $3(\mathrm{Cu})$ for TCL. While it was $7(\mathrm{SS})$ and $2(\mathrm{Cu})$ for UMP. A homogenized sample of biofilm with the cooling tower water was considered as Test 2. Upon propagation, staining with crystal violet, and subsequent calculation of absorbance rate in ELISA plate reader, the total absorbance of the 8 replicates was found to be 7 (SS) and $3(\mathrm{Cu})$ for TCL and it was $6(\mathrm{SS})$ and $2(\mathrm{Cu})$ for the UMP sample.

A significant decrease in the biofilm-forming potential was observed between the SS and $\mathrm{Cu}$ samples for both Test 1 and Test 2 . This might be due to the result of reduced activity emphasized by the copper antifouling coat present, in the autoinducer molecules as well as in the EPS structure. Z-score test was used to determinethe significance of difference between the biofilm-forming capabilities of both Test 1 and Test 2 samples and the result was significant at $\mathrm{p}<.05$ for both these tests. With the results obtained from the study, it can be concluded thatcopper coating demonstrated active antifouling efficacy against biofilm-forming organisms isolated from the cooling tower system. Hence, further studies on other autoinducer molecules produced by such organisms should be undertaken with a special focus on the signal molecules-targeted therapy and in quorumsensing manipulations. 


\section{Conclusion}

The uncontrollable formation of biofilm in industrial cooling towers has been a major problem for the past few decades. Chlorine and other biochemicals are the most preferred antifouling agentsto curtail the growth of sessile organisms. However, current research shows these chemicals do not exhibit adequate efficacy due to the emergence of resistance in the biofilm-forming organisms against such agents. Coating copper as an antifouling agent on the surface of the cooling tower has proved copper to be a potential proactive agent against biofouling. From the findings of study, it was concluded that effective use of copper antifouling paint can significantly reduce biofilm formation and its signaling molecules in industrial cooling towers and has the potential to create newer, more effectivealternatives for tacklingexisting biofilm problems in cooling towers and other similar setups.

Acknowledgment: The authors are thankful to the Principal, Faculty of Microbiology Department, Ethiraj College for Women, Chennai, and Thirumalai Chemicals Ltd and Ultra Marine and Pigments Ltd, Vellore, for providing the necessary facilities and support to carry out this research successfully.

\section{Ethical Clearance: NA}

Source of Funding: Meenakshi Academy of Higher Education and Research, Chennai, India

\section{Conflict of Interest: NA}

\section{References}

1. Probst AJ, Birarda G, Holman HY, DeSantis TZ, Wanner G, Andersen GL, Perras AK, Meck S, Völkel J, Bechtel HA, Wirth R. Coupling genetic and chemical microbiome profiling reveals heterogeneity of archaeome and bacteriome in subsurface biofilms that are dominated by the same archaeal species. PloS one. 2014 Jun 27;9(6):e99801.

2. Pal A, Paul AK. Microbial extracellular polymeric substances: central elements in heavy metal bioremediation. Indian journal of microbiology. 2008 Mar 1;48(1):49.

3. Donlan RM. Biofilm formation: a clinically relevant microbiological process. Clinical Infectious Diseases. 2001 Oct 15;33(8):1387-92.

4. Flemming HC. Biofouling in water systems-cases, causes and countermeasures. Applied microbiology and biotechnology. 2002 Sep 1;59(6):629-40.

5. Girard L, Blanchet É, Intertaglia L, Baudart J, Stien D, Suzuki M, Lebaron P, Lami R. Characterization of $\mathrm{N}$-acyl homoserine lactones in Vibrio tasmaniensis LGP32 by a biosensor-based UHPLC-HRMS/MS method. Sensors. 2017 Apr;17(4):906.

6. Türetgen I. Comparison of the efficacy of free residual chlorine and monochloramine against biofilms in model and full scale cooling towers. Biofouling. 2004 Apr 1;20(2):81-5.

7. Jahn A, Griebe T, Nielsen PH. Composition of Pseudomonas putida biofilms: accumulation of protein in the biofilm matrix. Biofouling. 1999 Jun 1;14(1):49-57.

8. Korber DR, Wolfaardt GM, Brözel V, MacDonald R, Niepel T. [1] Reporter systems for microscopic analysis of microbial biofilms. InMethod in enzymology 1999 Jan 1 (Vol. 310, pp. 3-20). Academic Press.

9. Meesters KP, Van Groenestijn JW, Gerritse J. Biofouling reduction in recirculating cooling systems through biofiltration of process water. Water Research. 2003 Feb 1;37(3):525-32.

10. Morikawa M, Kagihiro S, Haruki M, Takano K, Branda S, Kolter R, Kanaya S. Biofilm formation by a Bacillus subtilis strain that produces $\gamma$-polyglutamate. Microbiology. 2006 Sep 1;152(9):2801-7.

11. O'Toole GA. Microtiter dish biofilm formation assay. JoVE. 47.

12. Panjeshahi MH, Ataei A. Application of an environmentally optimum cooling water system design in water and energy conservation. International Journal of Environmental Science \& Technology. 2008 Mar 1;5(2):251-62.

13. Pellizzoni E, Ravalico F, Scaini D, Delneri A, Rizzo $\mathrm{R}$, Cescutti P. Biofilms produced by Burkholderia cenocepacia: Influence of media and solid supports on composition of matrix exopolysaccharides. Microbiology. 2016 Feb 1;162(2):283-94.

14. Sanmartín P, Aira N, Devesa-Rey R, Silva B, Prieto B. Relationship between color and pigment production in two stone biofilm-forming cyanobacteria (Nostoc sp. PCC 9104 and Nostoc sp. PCC 9025). Biofouling. 2010 Apr 27;26(5):499509. 
15. SHAKERI S, KASRA KR, EMTIAZI G. STUDY OF MICROCOCCUS LUTEUS BIOFILM FORMATION AND EVALUATION OF ANTIMICROBIAL EFFECTS ON ITS BIOFILM BY MICROTITER PLATE TEST.
16. Taghadosi R, Shakibaie MR, Masoumi S. Biochemical detection of N-Acyl homoserine lactone from biofilm-forming uropathogenic Escherichia coli isolated from urinary tract infection samples. Reports of biochemistry \& molecular biology. 2015 Apr;3(2):56. 